Check for updates

Cite this: RSC Adv., 2019, 9, 21355

Received 29th May 2019

Accepted 1st July 2019

DOI: $10.1039 / c 9 r a 04069 b$

rsc.li/rsc-advances

\section{High electrostrictive properties and energy storage performances with excellent thermal stability in $\mathrm{Nb}$-doped $\mathrm{Bi}_{0.5} \mathrm{Na}_{0.5} \mathrm{TiO}_{3}$-based ceramics $\uparrow$}

\author{
Yichen Wu, (D) ab Genshui Wang, ${ }^{\text {bcd }}$ Zheng Jiao, $^{\text {a }}$ Yuzhu Fan, ${ }^{\mathrm{b}}$ Ping Peng ${ }^{\mathrm{b}}$ \\ and Xianlin Dong ${ }^{\text {bcd }}$
}

\begin{abstract}
As a promising candidate material replacing $\mathrm{Pb}(\mathrm{ZrTi}) \mathrm{O}_{3}(\mathrm{PZT})$, the lead-free $\mathrm{Bi}_{0.5} \mathrm{Na}_{0.5} \mathrm{TiO}_{3}$ (BNT) system exhibits outstanding piezoelectric and ferroelectric properties. However, the weak thermal stability of these electric properties hampers its practical applications. In this work, we designed and prepared novel $\mathrm{Nb}$-doped $0.76 \mathrm{Bi}_{0.5} \mathrm{Na}_{0.5} \mathrm{TiO}_{3}-0.24 \mathrm{Bi}_{0.5} \mathrm{~K}_{0.5} \mathrm{TiO}_{3}$ (BNT-BKT) ceramics with superior temperature stability of electric properties. Both strain as well as discharging properties of $5 \% \mathrm{Nb}$-doped BNT-BKT ceramics varied less than $3 \%$ and $12.5 \%$ respectively from room temperature to $160{ }^{\circ} \mathrm{C}$, ascribed to the enlarged gap between the depolarized temperature $\left(T_{d}\right.$ or $\left.T_{F-R}\right)$ and the maximum dielectric temperature $\left(T_{m}\right)$. In addition, we investigated the impacts of $\mathrm{Nb}$ doping on the phase transition, dielectric, piezoelectric and ferroelectric behaviors of BNT-BKT ceramics in detail. Temperature dependent dielectric spectrums indicated that $T_{\mathrm{d}}$ decreased below room temperature with $\mathrm{Nb}$ modifying, revealing that the phase structure transformed from ferroelectric into ergodic relaxor. Accordingly, the maximum strain value of $0.21 \%$ and recoverable energy storage of $1.2 \mathrm{~J} \mathrm{~cm}^{-3}$ were simultaneously acquired at the critical composition of $5 \% \mathrm{Nb}$ incorporation. Our results provide an effective means of obtaining BNT-based ceramics with simultaneously thermally stable strain and discharge properties for wide temperature actuator and capacitor applications.
\end{abstract}

\section{Introduction}

Over the past decades, lead-based ceramics such as $\mathrm{PbMg}_{1 / 3} \mathrm{Nb}_{2 / 3} \mathrm{O}_{3^{-}}$ $\mathrm{PbTiO}_{3}$ (PMN-PT), Pb(ZrTi)O $\mathrm{O}_{3}$ (PZT) systems were widely investigated in applications of various electromechanical devices owing to their preeminent electric properties. ${ }^{1,2}$ However, taking into account the irreversible ecological harm caused by lead containing components, developing lead-free materials with alternative properties has inspired much efforts. In recent years, because of their high Curie temperature $\left(320^{\circ} \mathrm{C}\right)$ as well as large spontaneous polarization $(\sim 38$ $\left.\mu \mathrm{m} \mathrm{C}^{-1}\right),{ }^{3} \mathrm{Bi}_{0.5} \mathrm{Na}_{0.5} \mathrm{TiO}_{3}$ (BNT) ceramics with superior electromechanical performances have received widespread attention. Nevertheless, the high loss and large coercive field $\left(E_{\mathrm{c}}\right)$ due to the

${ }^{a}$ School of Environmental and Chemical Engineering, Shanghai University, Shanghai 200444, China

${ }^{b}$ Key Laboratory of Inorganic Functional Materials and Devices, Shanghai Institute of Ceramics, Chinese Academy of Sciences, Shanghai 200050, China. E-mail: genshuiwang@mail.sic.ac.cn

'The State Key Lab of High Performance Ceramics and Superfine Microstructure, Shanghai Institute of Ceramics, Chinese Academy of Sciences, Shanghai 200050, China

${ }^{d}$ Center of Materials Science and Optoelectronics Engineering, University of Chinese Academy of Sciences, Beijing 100049, China

$\dagger$ Electronic supplementary information (ESI) available. See DOI: $10.1039 / \mathrm{c} 9 \mathrm{ra} 04069 \mathrm{~b}$ vaporization of the Bi element result in impaired electric properties of BNT-based ceramics, hampering their practical applications. ${ }^{4}$

A number of binary systems were designed to improve the electric performances of $\mathrm{BNT}$ ceramics, for instance, $\mathrm{Bi}_{0.5^{-}}$ $\mathrm{Na}_{0.5} \mathrm{TiO}_{3}-\mathrm{Bi}_{0.5} \mathrm{~K}_{0.5} \mathrm{TiO}_{3} \quad(\mathrm{BNT}-\mathrm{BKT}), \quad \mathrm{Bi}_{0.5} \mathrm{Na}_{0.5} \mathrm{TiO}_{3}-\mathrm{BaTiO}_{3}$ (BNT-BT) and $\mathrm{Bi}_{0.5} \mathrm{Na}_{0.5} \mathrm{TiO}_{3}-\mathrm{K}_{0.5} \mathrm{Na}_{0.5} \mathrm{NbO}_{3}$ (BNT-KNN), etc. ${ }^{5}$ Among these binary components, BNT-BKT systems demonstrate prominent piezoelectric performances with comprehensive superior electric field-induced strain (EFIS) and piezoelectric constant $\left(d_{33}\right) .{ }^{6}$ Especially, Tan et al. ${ }^{7}$ obtained giant strain value of $0.7 \%$ in $\left(\left(\mathrm{Bi}_{1 / 2}\left(\mathrm{Na}_{0.84} \mathrm{~K}_{0.16}\right)_{1 / 2}\right)_{0.96} \mathrm{Sr}_{0.04}\right)(-$ $\left.\mathrm{Ti}_{1-x} \mathrm{Nb}_{x}\right) \mathrm{O}_{3}$ ceramics at ambient temperature. Moreover, due to its intrinsic large saturated polarization, the BNT-BKT systems also provide great potential in the applications of energy storage fields. ${ }^{8}$ Nevertheless, despite aforementioned competitive properties at room temperature, these performances will dramatically deteriorate when the temperature increases, unacceptable for realistic industrial applications and further restricting its development process. Up to now, the thermal stability of BNT-based ceramics is generally poor, and scarcely any attention has been focused on the weak thermal stability of them. ${ }^{9}$

For the past few years, several approaches had been done to improve the piezoelectric thermal stability of BNT-based ceramics through raising the depolarized temperature $\left(T_{\mathrm{d}}\right)$ to 
a higher level to form an enlarged temperature range between RT and $T_{\mathrm{d}}$, such as 0 -3-type composites, ${ }^{\mathbf{1 0}}$ hot-pressed sintering (HPS), ${ }^{11}$ and quenching process, ${ }^{12}$ etc. The increased $T_{\mathrm{d}}$ improves the thermal stability of piezoelectricity and applies the BNT-based devices to high temperature accelerometers. With the rapid developments of actuators and capacitors recently, the requirements to enhance the thermal stability of strain and energy storage properties are also extremely urgent. Inspired by the strategy of raising the $T_{\mathrm{d}}$ to enhance the thermal stability of piezoelectricity mentioned above, lowering the $T_{\mathrm{d}}$ could enlarge the temperature range between $T_{\mathrm{d}}$ and $T_{\mathrm{m}}$ of strain performances and consequently contribute to the thermal stability of the strain properties. Lately, a great many studies demonstrated that $\mathrm{Nb}$ doping in BNT system could effectively break the longrange order, changing the nonergodic polar nanoregions (PNRs) into ergodic ones. ${ }^{13}$ Furthermore, the addition of $\mathrm{Nb}$ would decrease the $T_{\mathrm{d}}$ below room temperature while maintain the maximum dielectric temperature $\left(T_{\mathrm{m}}\right)$, resulting to the extended temperature range between $T_{\mathrm{d}}$ and $T_{\mathrm{m}} \cdot{ }^{14}$ In addition, a dielectric plateau would form with the increase of $\mathrm{Nb}$ content, conducive to the thermal stability of energy storage properties. Therefore, simultaneously thermally stable strain and energy storage behaviors are expected to be obtained in Nb-doped BNTbased ceramics.

In this work, novel Nb-doped 0.76BNT-0.24BKT binary solutions were prepared. The microstructure, dielectric, piezoelectric and ferroelectric properties were studied in detail. The maximum value of strain of $0.21 \%$ and energy storage density of $1.2 \mathrm{~J} \mathrm{~cm}^{-3}$ were simultaneously acquired at 5\% doped BNT-BKT ceramics. To evaluate its thermal stability specifically, temperature-dependent strain and discharging properties were also investigated for actual application assessment. The results demonstrate that the strain and discharging properties vary below $3 \%$ and $12.5 \%$ respectively between 20 and $160{ }^{\circ} \mathrm{C}$ at $5 \%$ $\mathrm{Nb}$ doped BNT-BKT component, demonstrating its appropriate industrial applications in high temperature conditions.

\section{Experimental procedure}

The $0.76 \mathrm{BNT}-0.24 \mathrm{BKT}+x \mathrm{Nb}(x=1 \%, 3 \%, 5 \%, 7 \%$, abbreviated as $1 \mathrm{Nb}, 3 \mathrm{Nb}, 5 \mathrm{Nb}, 7 \mathrm{Nb}$, respectively) ceramics were fabricated through solid-state reaction method. Weighed according to the stoichiometry, powders of reagent-grade $\mathrm{Bi}_{2} \mathrm{O}_{3}$ (99.99\%),

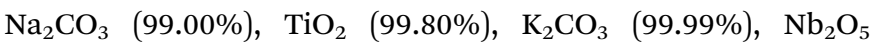
(99.38\%) were mixed with agate media and anhydrous ethanol followed by ball-milling for $24 \mathrm{~h}$. Subsequently, the powders were calcined at $850{ }^{\circ} \mathrm{C}$ in an air environment. The calcined powders needed ball-milling for $24 \mathrm{~h}$ one more time for the sake of the fine particle size. After that, the polyvinyl alcohol PVA was added as binder for granulation. Disks of $13 \mathrm{~mm}$ in diameter and $2 \mathrm{~mm}$ in thickness were prepared through uniaxial pressing under $150 \mathrm{MPa}$. After burning out the binder at $750{ }^{\circ} \mathrm{C}$, the samples were sintered at $1150-1200{ }^{\circ} \mathrm{C}$ for $2 \mathrm{~h}$ in an air atmosphere. In order to avoid the volatile elements of $\mathrm{Na}, \mathrm{Bi}$ and $\mathrm{K}$, the ceramics were buried in the corresponding powders in the sintering process. For the purpose of electric measurements, circular silver electrodes were coated on both sides of the polished samples.

X-ray diffraction (XRD, D/MAX-2550V; Rigaku, Tokyo, Japan) was utilized to analyze the phase structure of the ceramics. Micrographs of the polished and thermal etched surface was observed by scanning electron microscope (FESEM, Magellan400, FEI Company). Energy dispersive spectrometer (EDS) analysis was gathered from the attachment of the FESEM. The temperature dependence dielectric constant and tangent loss were tested by Hewlett Packard LCR meter. The polarizationelectric hysteresis $(P-E)$ loops, current-electric $(I-E)$ loops as well as the strain curves are measured using a ferroelectric measurement system (aixACCT TF Analyzer 2000, Aachen, Germany). The charging-discharging properties were tested by a designed RC load circles.

\section{Results and discussion}

\subsection{Phase formation and microstructure}

Fig. 1a displays the XRD patterns of $x \mathrm{Nb}$ ceramics at room temperature. As shown, the ceramics exhibit pure perovskite structure without any secondary phases when $x \leq 5 \%$. However, with further increase of $\mathrm{Nb}$ content to $x=7 \%$, the impurity phase $\mathrm{K}_{2} \mathrm{Ti}_{6} \mathrm{O}_{13}$ (PDF\#40-0403) is obviously observed as indexed in Fig. $\mathrm{S} 1, \uparrow$ demonstrating the solid solution limit of $5 \%$. Fig. $1 \mathrm{~b}$ and (c) display the enlarged (111) and (200) peaks around $40^{\circ}$
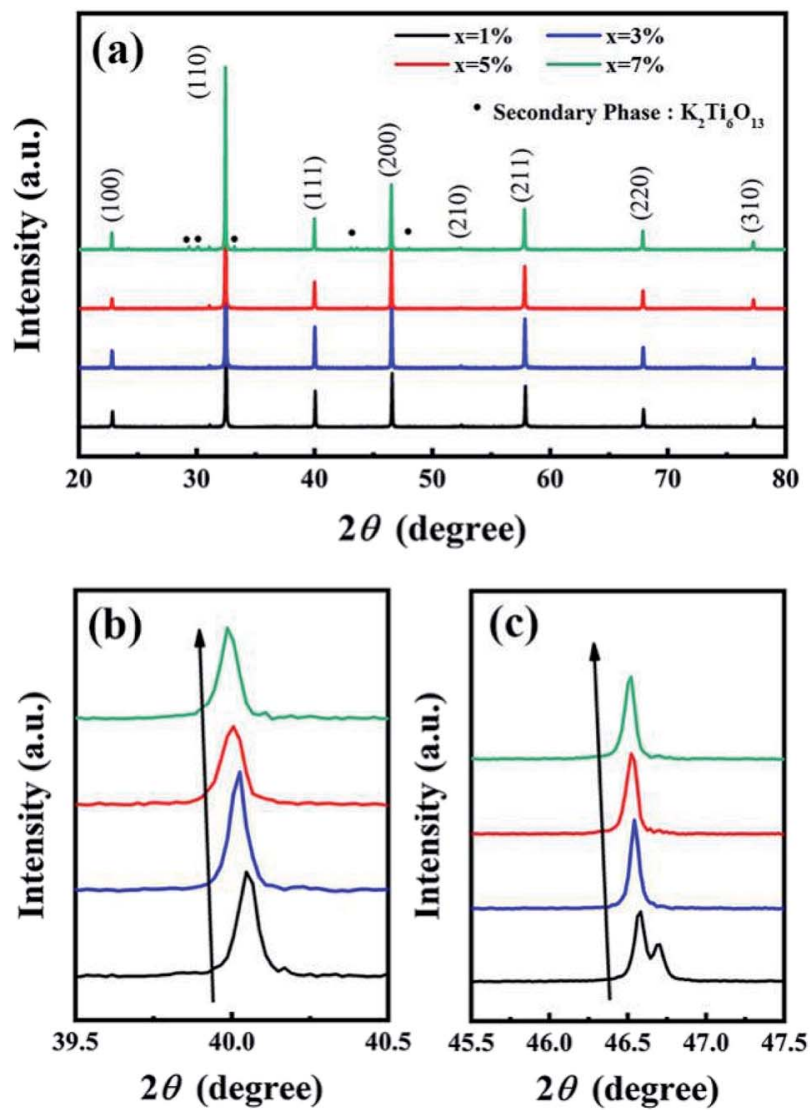

Fig. 1 (a) XRD patterns of $x \mathrm{Nb}$ ceramics. (b and c) Enlarged (111) and (200) peaks around $40^{\circ}$ and $46^{\circ}$, respectively. 
and $46^{\circ}$, it can be observed that these two reflection peaks shift to lower angles, consistent with the larger $\mathrm{Nb}^{5+}$ ions replacing the $\mathrm{Ti}^{4+}$ ions with smaller radius $\left[\mathrm{Ti}^{4+}(0.604 \AA, \mathrm{CN}=6)\right.$, $\left.\mathrm{Nb}^{5+}(0.64 \AA, \mathrm{CN}=6)\right]$ at B-sites. ${ }^{15}$ The phase structure of the ceramics transforms from $P 4 \mathrm{~mm}$ at $1 \mathrm{Nb}$ ceramics to pseudocubic structure with higher $\mathrm{Nb}$ content, evidenced from the fact that the $(200) /(002)$ peaks merge into a single $(200)_{\mathrm{pc}}$ peak. ${ }^{16}$

Fig. 2 display the SEM images of the polished and thermaletched surface. The samples exhibit homogeneous and dense microstructures for compositions up to $x=5 \%$. The secondary phase obviously appears with the further increase of $\mathrm{Nb}$ content to $x=7 \%$. The results of the element spot scanning measured by EDS demonstrate that the secondary phase is $\mathrm{Bi}$ and $\mathrm{Na}$ deficient and $\mathrm{K}$ enriched phase, as shown in Fig. $\mathrm{S} 2 \dagger$ and Table $\mathrm{S} 1, \uparrow$ which is consistent with the $\mathrm{K}_{2} \mathrm{Ti}_{6} \mathrm{O}_{13}$ phase determined by XRD. In addition, the average grain size doesn't display significant composition dependence with the similar average grain size $\sim 2.3 \mu \mathrm{m}$ measured through linear intercept method. The independence between composition and grain size indicates that the variation of strain and energy storage properties have no relation to the size of grain.

\subsection{Dielectric properties}

Fig. 3 presents the temperature dependence of dielectric constant $(\varepsilon)$ and loss $(\tan \delta)$ for poled ceramics under varied frequencies. Three significant dielectric abnormal peaks appear at $T_{\mathrm{F}-\mathrm{R}}, T_{\mathrm{s}}$ and $T_{\mathrm{m}}$. The $T_{\mathrm{F}-\mathrm{R}}$ (equal to the depolarized temperature $T_{\mathrm{d}}$ ) reflects the ferroelectric to relaxor transition temperature, indicating that the ferroelectric $P 4 \mathrm{~mm}$ domains change into relaxor $\mathrm{P} 4 \mathrm{bm}$ polar nanodomains (PNRs) during heating. However, no $T_{\mathrm{F}-\mathrm{R}}$ could be found in the dielectric curves when $x$ $\geq 3 \%$, indicating that the $T_{\mathrm{F}-\mathrm{R}}$ is below room temperature and the ceramics have changed into the relaxor phase with $\mathrm{p} 4 \mathrm{bm}$ nanodomains at room temperature. ${ }^{17}$ The difference of phase structure obtained from XRD and $\varepsilon-T$ curves is ascribed to the fact that the nanoscale structure could not detected by XRD accurately. ${ }^{18}$ These nanodomains would grow into ferroelectric domains under electric field, conductive to large strain and energy storage properties. The $T_{\mathrm{s}}$, which is related to the thermal evolution of tetragonal PNRs, also decreases with increase of the $\mathrm{Nb}$ content. It's noteworthy that the $\varepsilon$ merges immediately as the temperature increase above $T_{\mathrm{s}}$, revealing the disappearance of relaxor characteristics as well as the relation between $T_{\mathrm{s}}$ and the relaxor behavior in this system. With the temperature further increasing, the maximum dielectric constant $\varepsilon_{\mathrm{m}}$ appears at around $280{ }^{\circ} \mathrm{C}$, which is usually defined as $T_{\mathrm{m}}\left(T_{\mathrm{c}}\right)$. The barely changed $T_{\mathrm{m}}$ accompanied by notably decreased $T_{\mathrm{F}-\mathrm{R}}$ results in the widened gap between $T_{\mathrm{F}-\mathrm{R}}$ and $T_{\mathrm{m}}$, as shown in Fig. 4. Furthermore, with the increasing $\mathrm{Nb}$ content, the dielectric constant maximum $\varepsilon_{\mathrm{m}}$ decreases sharply, getting closer to the dielectric constant value at $T_{\mathrm{s}}$ and resulting in the formation of dielectric plateau in a wide temperature range. ${ }^{19}$ The temperature independence of the dielectric properties is closely related to the thermal stability of electric behaviors. ${ }^{19}$

\subsection{Electrostrain properties}

Fig. 5a exhibits the bipolar strain behaviors of $x \mathrm{Nb}$ ceramics under $5 \mathrm{kV} \mathrm{mm}^{-1}$ and $10 \mathrm{~Hz}$. The $1 \mathrm{Nb}$ ceramics exhibit typical butterfly-shaped bipolar $S-E$ curves with a positive strain $\left(S_{\text {pos }}\right)$ of $0.12 \%$ and negative strain $\left(S_{\text {neg }}\right)$ of $0.1 \%$, which is the characteristic of ferroelectrics as the negative strain is related to the
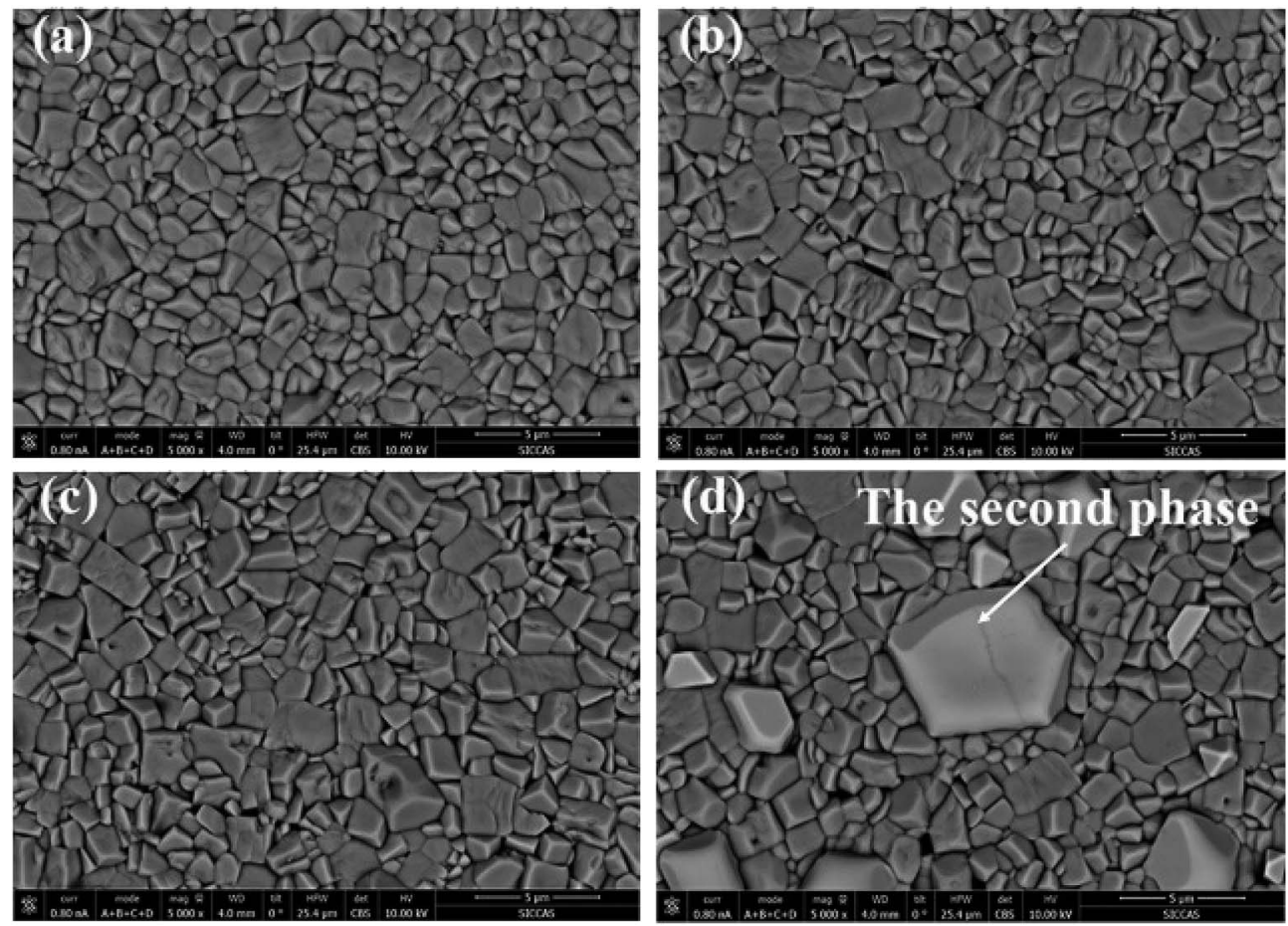

Fig. 2 The scanning electron microscopy photographs of $x$ Nb doped BNT-BKT ceramics with (a) $x=1 \%$, (b) $x=3 \%$, (c) $x=5 \%$, (d) $x=7 \%$. 

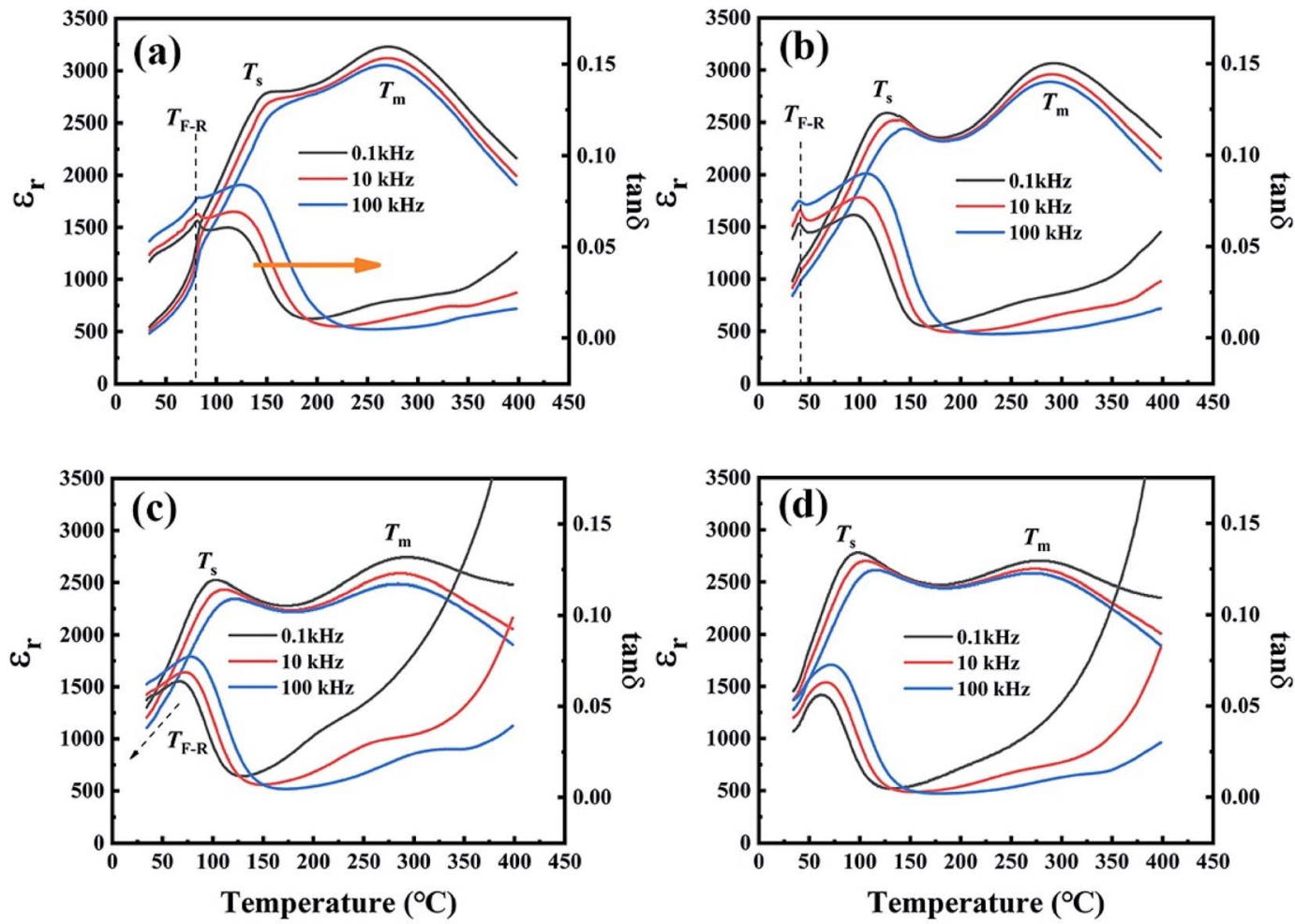

Fig. 3 Temperature dependent dielectric curves of $x \mathrm{Nb}$ ceramics for (a) $x=1 \%$, (b) $x=3 \%$, (c) $x=5 \%$, (d) $x=7 \%$ component.

domain back switching during loading electric field. ${ }^{20}$ With the increase of Nb content, it could be clearly observed that the $S_{\text {neg }}$ has been declining to 0 while the $S_{\text {pos }}$ rises significantly. As illustrated in Fig. 5b, the $S_{\text {pos }}$ and $S_{\text {neg }}$ value reach the maximum of $0.19 \%$ and the minimum of 0 respectively at $5 \mathrm{Nb}$ ceramics. As the $\mathrm{Nb}$ content reaches $7 \%$, the $S_{\text {pos }}$ value drops to $0.12 \%$ and

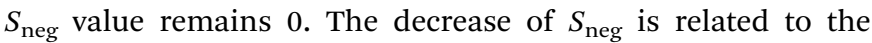
reduction of the domain wall density induced by the $\mathrm{Nb}$ modifying, while the ultimate vanishment of which indicates that $\mathrm{Nb}$-doped BNKT ceramics have changed into the ergodic relaxor ferroelectrics, in good agreement with dielectric curves.

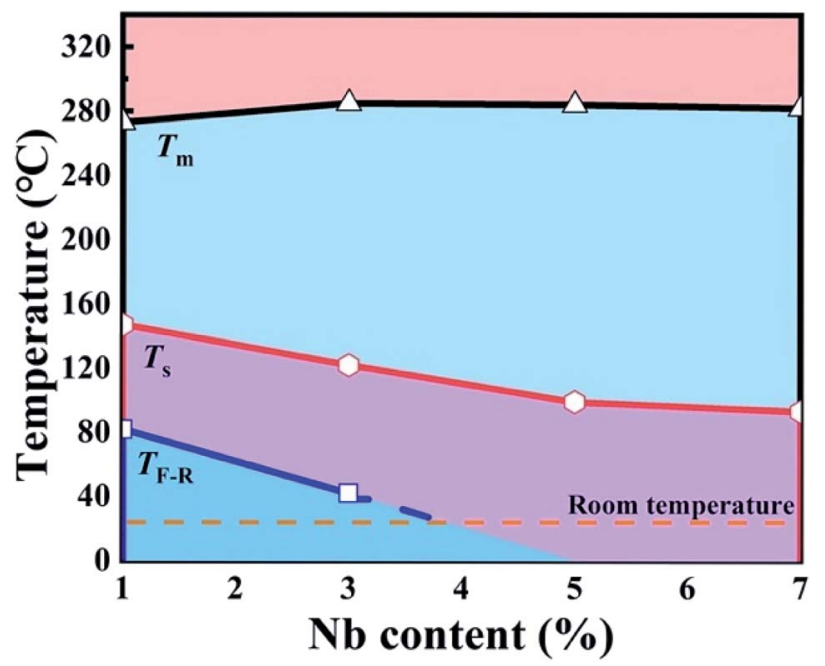

Fig. 4 Phase diagram of $x \mathrm{Nb}$ ceramics.
To assess the suitability of the designed ceramics in actuator applications, unipolar strain curves are depicted in Fig. 5c. On increasing the $\mathrm{Nb}$ content from $1 \%$ to $5 \%$, the strain value increases from $0.10 \%$ to $0.21 \%$, and decreases subsequently to $0.11 \%$ at $x=7 \%$. To better explain the physical mechanism of the strain, the $d_{33}$ as well as normalized strain $S_{\max } / E_{\max }\left(d_{33}^{*}\right)$ of the $x \mathrm{Nb}$ ceramics were measured and analyzed, as shown in Fig. $5 \mathrm{~d}$. The BNKT ceramics exhibit large $d_{33}$ of $180 \mathrm{pC} / \mathrm{N}$, in proximity with its $d_{33}^{*}$ of $200 \mathrm{pm} \mathrm{V}^{-1}$, indicating that the strain value of $1 \mathrm{Nb}$ ceramics mainly origins from the converse piezoelectric effect. With the increase of $\mathrm{Nb}$ doping, the $d_{33}$ keeps reducing until nearly $0 \mathrm{pC} / \mathrm{N}$ at $7 \mathrm{Nb}$ ceramics while the $d_{33}^{*}$ increases sharply reaching the maximum value of $420 \mathrm{pm} \mathrm{V}^{-1}$ at $x=5 \%$, and eventually it reduces to $200 \mathrm{pm} \mathrm{V}^{-1}$ at $x=7 \%$. This phenomenon reveals that the strain property mainly origins from the electric field induced relaxor and ferroelectric phase transition because of their low energy barrier. ${ }^{21}$ The decrease of strain at $x=7 \%$ is caused by the enlarged energy barrier of the phase transition.

For the purpose of evaluating the thermal stability of the strain behavior, temperature dependent unipolar strain curves of the $5 \mathrm{Nb}$ component are characterized. As depicted in Fig. $6 \mathrm{a}$, the $5 \mathrm{Nb}$ ceramics possess excellent thermal stability of the strain behavior, almost maintaining the fixed value in the measured temperature region of $20-160{ }^{\circ} \mathrm{C}$ with the variation less than $3 \%$. The excellent thermal stability of this strain property is much superior than many other systems, ${ }^{22-25}$ as displayed in Fig. 7. The excellent temperature independence of strain value of our $5 \mathrm{Nb}$ ceramics demonstrates its advantages in practical applications of actuators. Meanwhile, as shown in Fig. 6b, the strain hysteresis of these unipolar curves decreases 

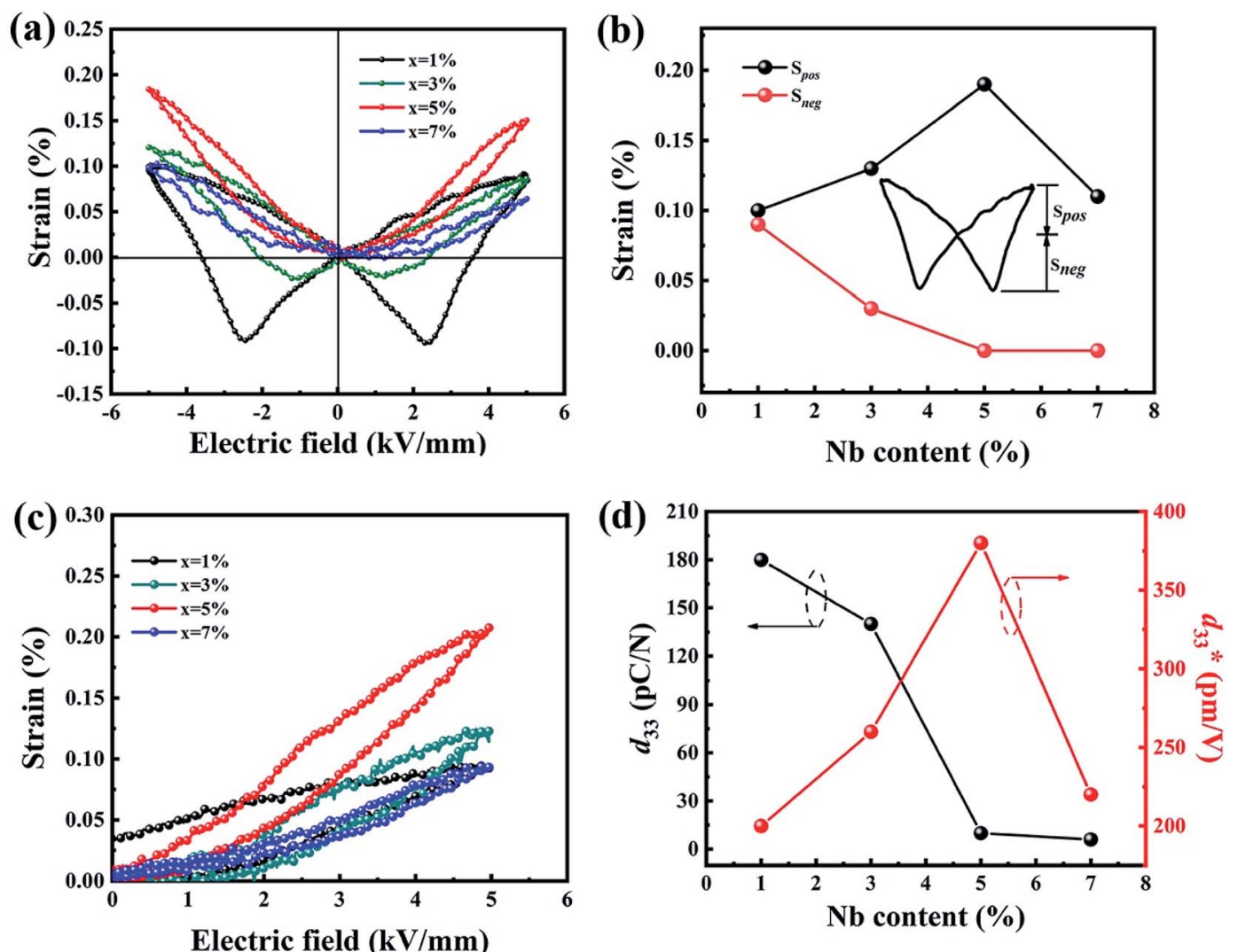

Fig. 5 The component dependent (a) bipolar strain and (c) unipolar strain curves of $x \mathrm{Nb}$ ceramics under $5 \mathrm{kV} \mathrm{mm} \mathrm{mm}^{-1}$. (b) The evolution of component dependent $S_{\text {neg }}$ and $S_{\text {pos. }}$ (d) The component dependent piezoelectric constant $d_{33}$ and normalized strain $d_{33}^{*}$.

sharply from $24 \%$ to 0 with the temperature increasing. It is worth noting that the strain value maintains a high level near $T_{\mathrm{s}}$ while the hysteresis is zero. This is an interesting phenomenon, because if the subsequent work can adjust the $T_{\mathrm{S}}$ to room temperature, the BNT-based ceramics with both high strain and ultra-low hysteresis can be obtained, which has great application prospects.

\subsection{Energy storage properties}

To characterize the energy storage performances of the ceramics, $P-E$ loops under critical electric field of $12 \mathrm{kV} \mathrm{mm}^{-1}$ of different content of $\mathrm{Nb}$ are displayed in Fig. 8. The $1 \% \mathrm{Nb}$ modified BNKT ceramics exhibit typical saturated ferroelectric performance with both large $P_{\mathrm{m}}$ and $P_{\mathrm{r}}$ of $48 \mu \mathrm{C} \mathrm{cm}^{-2}$ and $40 \mu \mathrm{C}$ $\mathrm{cm}^{-2}$ respectively, corresponding to its butterfly-shaped strain curves. With the $\mathrm{Nb}$ content increasing to $5 \%$, the $P_{\mathrm{r}}$ reduces dramatically accompanied by the decline of $P_{\mathrm{m}}$, resulting in the pinched $P-E$ loops. The obvious changes of $P-E$ loops confirm that the long-range ferroelectric order of BNKT ceramics has been disrupted into ergodic relaxor (ER) phase. ${ }^{26}$ As the $\mathrm{Nb}$ content further increases to $7 \%$, the critical electric field for the phase transition between relaxor and ferroelectric increases

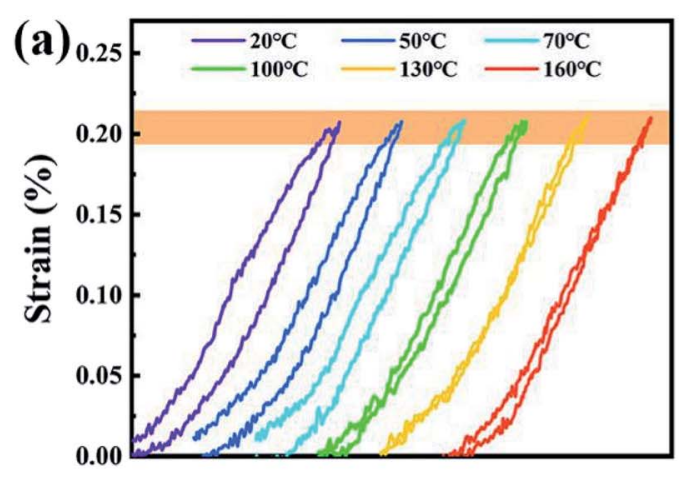

Electric field $=\mathbf{5 k V} / \mathbf{m m}$

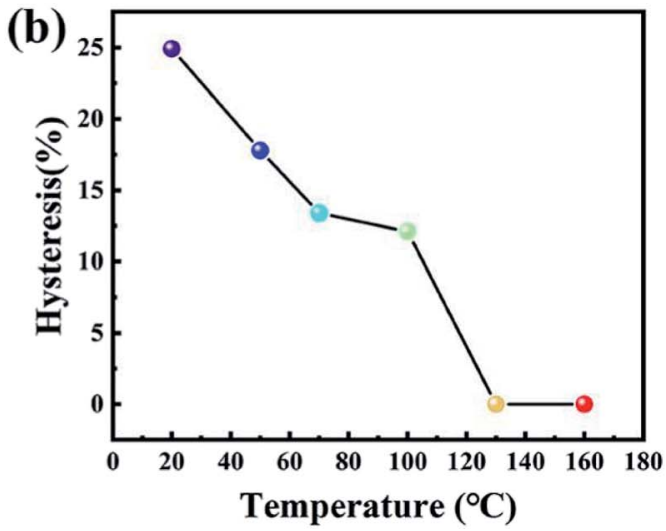

Fig. 6 The temperature dependent (a) the strain value of $5 \mathrm{Nb}$ ceramics and (b) the corresponding hysteresis. 


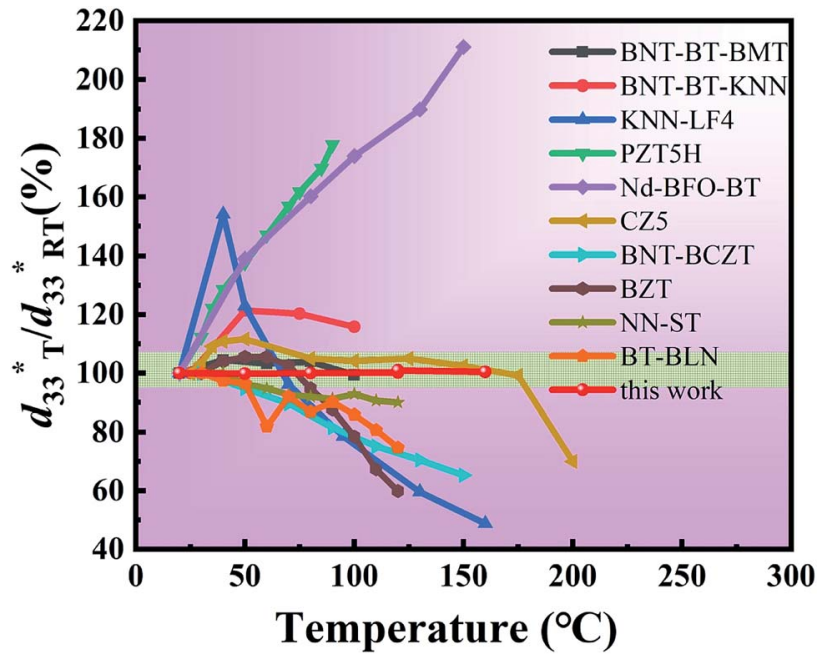

Fig. 7 Comparison of the temperature dependence of the $d_{33}^{*}$ as normalized to the $d_{33, \mathrm{RT}}^{*}$ for various systems.

sharply, evidenced by the quasi-linear loops with relatively low $P_{\mathrm{m}}$. Fig. 8b presents the corresponding current-electric field (I$E$ ) loops. As is displayed, the 1\% doped BNKT ceramics show typical ferroelectric $I-E$ curves with two sharp current switching peaks. The inherent ferroelectric order exists stably even when the electric field is withdrawn, manifested in the large $P_{\mathrm{r}}$. On increasing the $\mathrm{Nb}$ content to $3 \%$, four current peaks $\left(\mathrm{P}_{1}, \mathrm{P}_{2}, \mathrm{P}_{3}\right.$, $\mathrm{P}_{4}$ ) appear, ${ }^{6,26}$ it's reported that these four current peaks are related to the ER phase induced by the $\mathrm{Nb}$ content modifying. The ER phase would transform into metastable ferroelectric phase under exerted electric field, corresponding to $\mathrm{P}_{1} / \mathrm{P}_{3}$ current peaks, resulting in large $P_{\mathrm{m}}$. When removing the electric field, the induced long-range order would change back to the initial ER state, corresponding to $\mathrm{P}_{2} / \mathrm{P}_{4}$ current peaks, resulting in the low $P_{\mathrm{r}}$. Both large $P_{\mathrm{m}}$ and low $P_{\mathrm{r}}$ are beneficial to acquire high energy storage property. According to the formula: ${ }^{18,27,28}$

$$
\text { Energy storage density }(W)=\int_{0}^{P \max } E \mathrm{~d} P
$$

$$
\begin{gathered}
\text { Recoverable energy storage density }\left(W_{\mathrm{rec}}\right)=\int_{P \mathrm{r}}^{P \max } E \mathrm{~d} P \\
\text { Energy storage efficiency }(\eta)=(W) \frac{W \mathrm{rec}}{W} \times 100 \%
\end{gathered}
$$

Where $P, P_{\mathrm{m}}, P_{\mathrm{r}}$, and $E$ indicate the polarization, maximum polarization, remnant polarization, and exerted electric field, respectively. $P_{\mathrm{m}}$ and $P_{\mathrm{r}}$ play important role in improving the value of $W_{\text {rec }}$. Thus we summarized the $P_{\mathrm{m}}, P_{\mathrm{r}}$ and $\Delta P\left(P_{\mathrm{m}}-P_{\mathrm{r}}\right)$ in Fig. 8c. When increasing $\mathrm{Nb}$ content from $1 \%$ to $7 \%, P_{\mathrm{m}}$ smoothly decreases from $48 \mu \mathrm{C} \mathrm{cm}^{-2}$ to $27 \mu \mathrm{C} \mathrm{cm}^{-2}$ while $P_{\mathrm{r}}$ sharply reduces from $40 \mu \mathrm{C} \mathrm{cm}^{-2}$ to $3 \mu \mathrm{C} \mathrm{cm}^{-2}$. As a result, the $\Delta P$ achieves the maximum value of $32 \mu \mathrm{C} \mathrm{cm}^{-2}$ at $5 \mathrm{Nb}$ ceramics, boosting high $W_{\text {rec }}$ of $1.2 \mathrm{~J} \mathrm{~cm}^{-3}$ in this component, as shown in Fig. 8d. In addition, the $\eta$ value keeps increasing until $x=7 \%$, ascribed to the reduced hysteresis of $P-E$ loops.

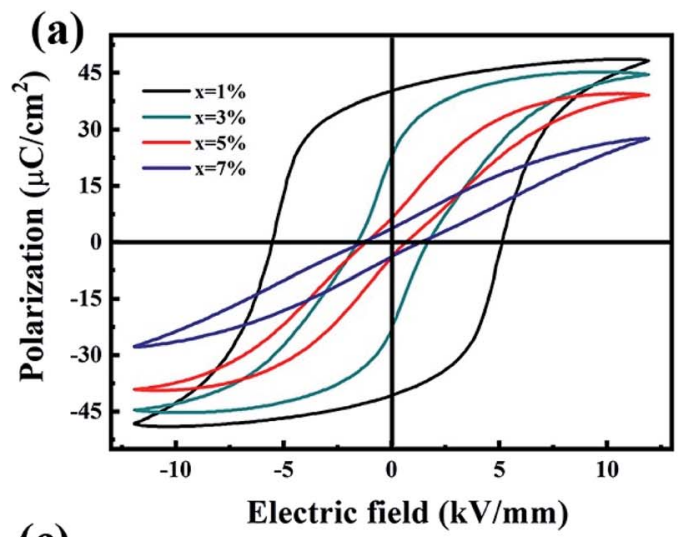

(c)
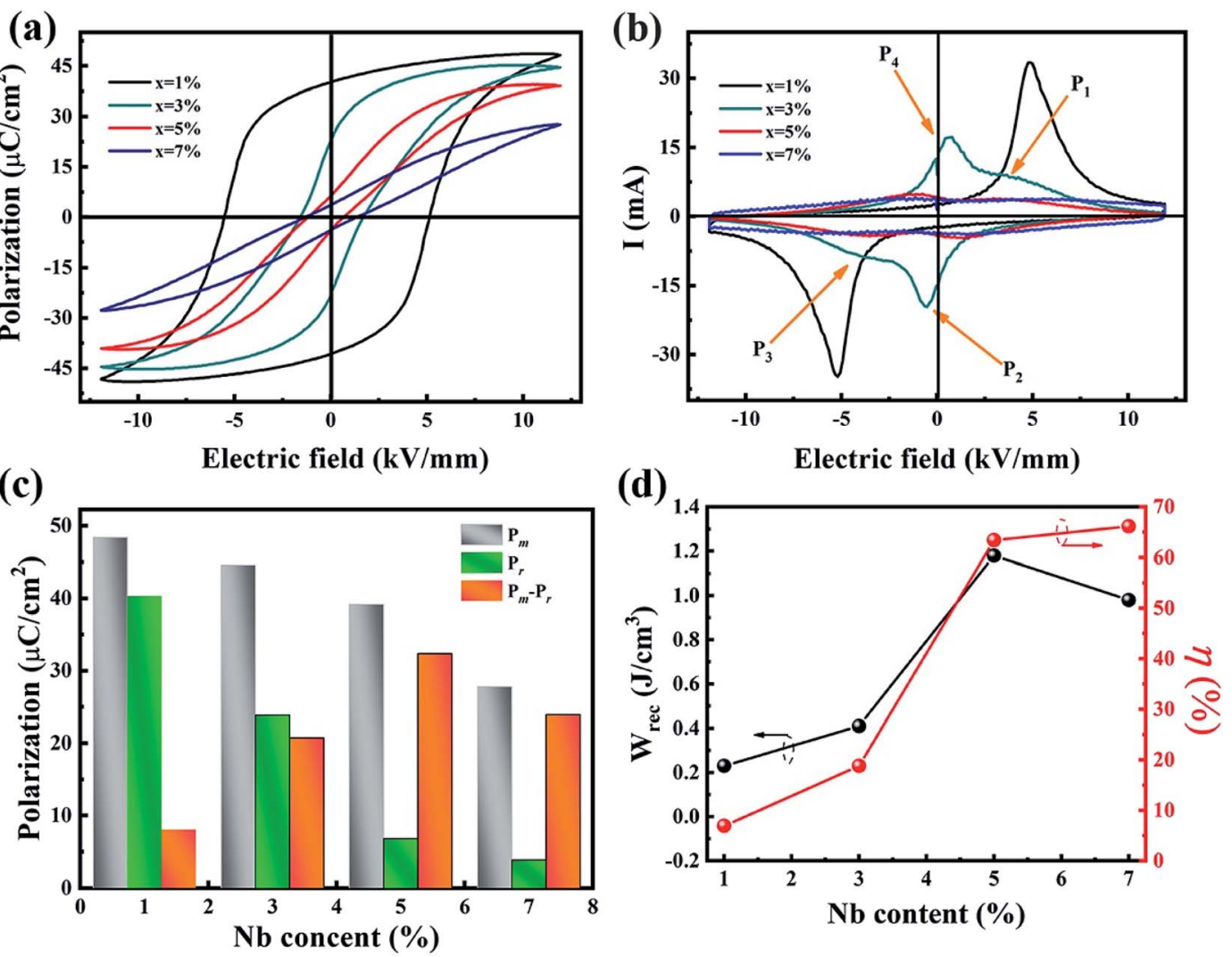

Fig. 8 (a) $P-E$ loops of $x \mathrm{Nb}$ ceramics and (b) corresponding $/-E$ curves at room temperature. (c) The component dependent $P_{\mathrm{m}}, P_{\mathrm{r}}$ and $\Delta P\left(P_{\mathrm{m}}-\right.$ $P_{r}$ ). (d) The component dependent calculated energy storage density and efficiency. 
(a)

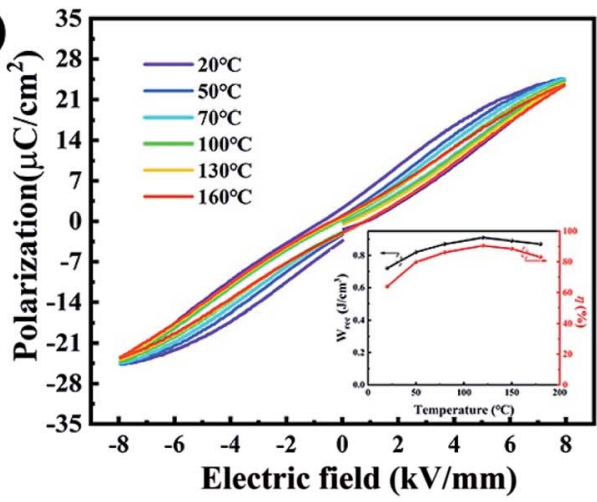

(c)

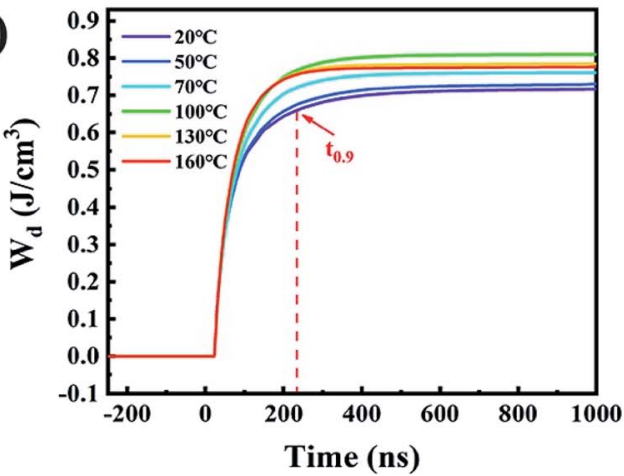

(b)

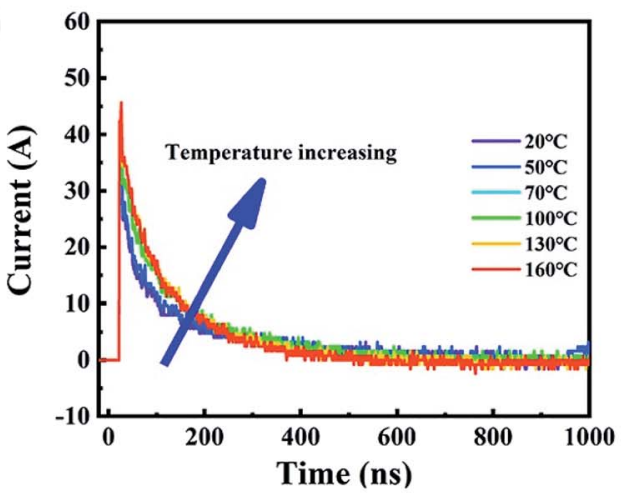

(d)

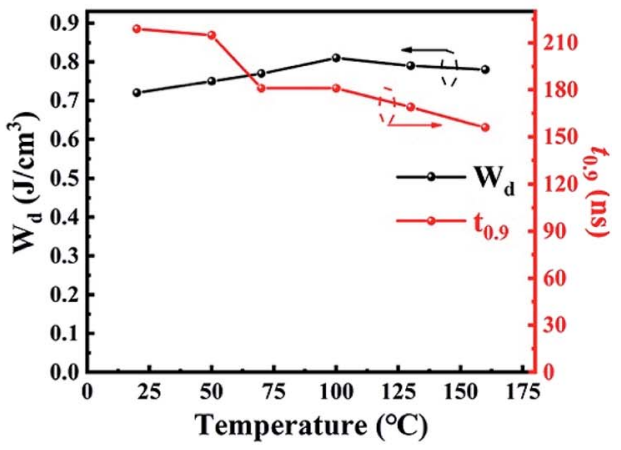

Fig. 9 (a) The temperature dependent $P-E$ loops of $5 \mathrm{Nb}$ ceramics at $8 \mathrm{kV} \mathrm{mm}{ }^{-1}$, the inset shows corresponding $W_{\text {rec }}$ and $\eta$. (b) Overdamped discharging current curves of the $5 \mathrm{Nb}$ ceramis at $8 \mathrm{kV} \mathrm{mm}^{-1}$. (c) The calculated $W_{\mathrm{d}}-t$ curves. (d) The summarized $W_{\mathrm{d}}$ and $t_{0.9}$ values as a function of temperature.

\subsection{Charging-discharging properties}

To assess the temperature stability of the $5 \mathrm{Nb}$ ceramics, temperature dependent $P-E$ loops at $8 \mathrm{kV} \mathrm{mm}^{-1}$ are depicted in Fig. 9a. The ferroelectric properties exhibit stable trend with the polarization value $\left(P_{\mathrm{m}}\right.$ and $\left.P_{\mathrm{r}}\right)$ exhibiting little changes in the measured temperature range from 20 to $160{ }^{\circ} \mathrm{C}$, as displayed in the inset of Fig. 9a. To evaluate the practical application performances, temperature dependent overdamped discharge current curves of the $5 \mathrm{Nb}$ ceramics under $8 \mathrm{kV} \mathrm{mm}^{-1}$ are illustrated in Fig. 9b. As shown, the $5 \mathrm{Nb}$ ceramics exhibit similar discharging performances under different temperature, with the current curves reaching the maximum value rapidly and lasting less than $1 \mu \mathrm{s}$. In the measuring temperature range, the current curves maintain the peak value of $46 \mathrm{~A}$, exhibiting excellent thermal stability. According to the formula $W_{\mathrm{d}}=R \int i(t)^{2} \mathrm{~d} t / V$, where the $R, \mathrm{~V}$ denote the total load resistor $(200 \Omega)$ and sample volume respectively, ${ }^{29}$ the calculated $W_{\mathrm{d}}-t$ value are illustrated in Fig. $9 c$. The $t_{0.9}$ indicated by the dash line in Fig. 9c means the time required to release $90 \%$ of the stored energy $\left(W_{\mathrm{d}}\right)$. It's noteworthy that the $W_{\mathrm{d}}$ and $t_{0.9}$ change from $0.72 \mathrm{~J} \mathrm{~cm}^{-3}$ and $124.8 \mathrm{~ns}$ to $0.81 \mathrm{~J} \mathrm{~cm}^{-3}$ and $121.6 \mathrm{~ns}$ respectively in the range of $20-160^{\circ} \mathrm{C}$, keeping the variation less than $12.5 \%$, as illustrated in Fig. 9d. The superior thermal stability of the $5 \mathrm{Nb}$ ceramics demonstrates its great potential in high temperature energy storage applications.

At present, the doping of elements mainly improves the temperature stability of strain or energy storage performances singly, and there are fewer materials simultaneously possessing

Table 1 The temperature stability of the investigated materials compared with other perovskite systems ${ }^{a}$

\begin{tabular}{|c|c|c|c|c|c|c|}
\hline Materials & Strain & Variation & $W_{\text {rec }}\left(\mathrm{J} \mathrm{cm}^{-3}\right)$ & Variation & Temperature range & References \\
\hline Ho doped BCZT & $\sim 0.165 \%$ & $<2 \%$ & - & - & $20-70{ }^{\circ} \mathrm{C}$ & 30 \\
\hline Sb doped KNN-SZ-BNZ & $\sim 0.14 \%$ & $<10 \%$ & - & - & $20-180^{\circ} \mathrm{C}$ & 31 \\
\hline BNT modified BT & - & - & 2.14 & $<12 \%$ & $25-175^{\circ} \mathrm{C}$ & 33 \\
\hline BFO modified BCT-BMT & - & - & 0.39 & $\sim 15 \%$ & $25-110^{\circ} \mathrm{C}$ & 34 \\
\hline BZS modified BT & - & - & $\sim 1.12$ & $<15 \%$ & $20-160^{\circ} \mathrm{C}$ & 35 \\
\hline
\end{tabular}

${ }^{a}$ PZT: $\mathrm{Pb}\left(\mathrm{Zr}_{0.53} \mathrm{Ti}_{0.47}\right) \mathrm{O}_{3}$ BCZT: $\left(\mathrm{Ba}_{0.85} \mathrm{Ca}_{0.15}\right)\left(\mathrm{Zr}_{0.1} \mathrm{Ti}_{0.9}\right) \mathrm{O}_{3} \mathrm{KNN}:\left(\mathrm{K}_{0.48} \mathrm{Na}_{0.52}\right) \mathrm{NbO}_{3}$ SZ: $\mathrm{SrZrO}_{3}$ BNZ: $\left(\mathrm{Bi}_{0.5} \mathrm{Na}_{0.5}\right) \mathrm{ZrO}_{3} \mathrm{BNKT} \mathrm{Bi}_{0.5}\left(\mathrm{Na}_{0.84} \mathrm{~K}_{0.16}\right)_{0.5} \mathrm{TiO}_{3} \mathrm{ST}$ : $\mathrm{SrTiO}_{3}$ BCT: $\mathrm{Ba}_{0.8} \mathrm{Ca}_{0.2} \mathrm{TiO}_{3}$ BMT: $\mathrm{BiMg}_{0.5} \mathrm{Ti}_{0.5} \mathrm{O}_{3}$ BZS:Bi $\left(\mathrm{Zn}_{0.5} \mathrm{Sn}_{0.5}\right) \mathrm{O}_{3}$. 
temperature and energy storage stability. Despite this, our Nbdoped BNT-based ceramics attained superior results in temperature stability in both strain and energy storage performances compared with other currently promising materials, as shown in Table $1 .^{30-35}$ Therefore, these results provide new strategies for the application researches of BNT-based ceramics.

\section{Conclusion}

In this work, we designed and prepared Nb modified BNT-based ceramics with excellent thermal stability through simple solidstate reaction method. Enhanced strain and energy storage properties $\left(0.21 \%\right.$ and $1.2 \mathrm{~J} \mathrm{~cm}^{-3}$ respectively) were obtained in $5 \mathrm{Nb}$ ceramics due to relaxor and ferroelectric phase transition. The extended temperature range between $T_{\mathrm{F}-\mathrm{R}}$ and $T_{\mathrm{m}}$ accompanied by wider dielectric plateau jointly contribute to the thermal stability of piezoelectric and discharging behaviors. As a result, the strain and discharge energy density of $5 \mathrm{Nb}$ component vary less than $3 \%$ and $12.5 \%$ respectively in the temperature range of $\mathrm{RT}$ and $160{ }^{\circ} \mathrm{C}$. The excellent temperature stability of $5 \mathrm{Nb}$ ceramics indicates its outstanding applications in the high temperature conditions of dielectric capacitors and actuators.

\section{Conflicts of interest}

There are no conflicts of interest to declare.

\section{Acknowledgements}

This work was supported by the National Natural Science Foundation of China (Grant No. 11774366, 51831010) and Natural Science Foundation of Shanghai (Grant No. 18ZR1444900).

\section{References}

1 J. Rödel, K. G. Webber, R. Dittmer, W. Jo, M. Kimura and D. Damjanovic, J. Eur. Ceram. Soc., 2015, 35, 1659-1681.

2 P. Baettig, C. F. Schelle, R. LeSar, U. V. Waghmare and N. A. Spaldin, Chem. Mater., 2005, 17, 1376-1380.

3 M. Davies, E. Aksel and J. L. Jones, J. Am. Ceram. Soc., 2011, 94, 1314-1316.

4 R. A. Malik, A. Hussain, A. Maqbool, A. Zaman, T. K. Song, W.-J. Kim and M.-H. Kim, J. Alloy. Comp., 2016, 682, 302-310.

5 G. Dong, H. Fan, J. Shi, M. Li and W. Jo, J. Am. Ceram. Soc., 2015, 98, 1150-1155.

6 X. Zhou, Z. Yan, H. Qi, L. Wang, S. Wang, Y. Wang, C. Jiang, H. Luo and D. Zhang, J. Eur. Ceram. Soc., 2019, 39, 23102317.

7 X. Liu and X. Tan, Adv. Mater., 2016, 28, 574-578.

8 Y. Wu, Y. Fan, N. Liu, P. Peng, M. Zhou, S. Yan, F. Cao, X. Dong and G. Wang, J. Mater. Chem. C, 2019, 7, 6222-6230.

9 L. Jin, W. Luo, L. Wang, Y. Tian, Q. Hu, L. Hou, L. Zhang, X. Lu, H. Du, X. Wei, G. Liu and Y. Yan, J. Eur. Ceram. Soc., 2019, 39, 277-286.
10 J. Zhang, Z. Pan, F. F. Guo, W. C. Liu, H. Ning, Y. B. Chen, M. H. Lu, B. Yang, J. Chen, S. T. Zhang, X. Xing, J. Rodel, W. Cao and Y. F. Chen, Nat. Commun., 2015, 6, 6615.

11 R. I. Mahdi and W. H. A. Majid, RSC Adv., 2016, 6, 8129681309.

12 Z.-T. Li, H. Liu, H.-C. Thong, Z. Xu, M.-H. Zhang, J. Yin, J.-F. Li, K. Wang and J. Chen, Adv. Electron. Mater., 2019, 5, 1800756.

13 K.-N. Pham, A. Hussain, C. W. Ahn, W. Kim, S. J. Jeong and J.-S. Lee, Mater. Lett., 2010, 64, 2219-2222.

14 L. Li, M. Zhu, Q. Wei, M. Zheng, Y. Hou and J. Hao, J. Eur. Ceram. Soc., 2018, 38, 1381-1388.

15 R. D. Shannon, Acta Crystallogr., 1976, A32, 751-767.

16 F. Li, K. Yang, X. Liu, J. Zou, J. Zhai, B. Shen, P. Li, J. Shen, B. Liu, P. Chen, K. Zhao and H. Zeng, Scripta Mater., 2017, 141, 15-19.

17 J. Wu, A. Mahajan, L. Riekehr, H. Zhang, B. Yang, N. Meng, Z. Zhang and H. Yan, Nano Energy, 2018, 50, 723-732.

18 W. Huang, Y. Chen, X. Li, G. Wang, N. Liu, S. Li, M. Zhou and X. Dong, Appl. Phys. Lett., 2018, 113, 203902.

19 F. Hu, X. Chen, P. Peng, F. Cao, X. Dong and G. Wang, J. Am. Ceram. Soc., 2018, 101, 4434-4440.

20 Z. Rashad and A. Feteira, Mater. Lett., 2018, 222, 180-182.

21 L. Wang, R. Liang, Z. Zhou and X. Dong, Scripta Mater., 2019, 164, 62-65.

22 J. Hao, W. Li, J. Zhai and H. Chen, Mater. Sci. Eng., R, 2019, 135, 1-57.

23 L. Jin, J. Qiao, L. Wang, L. Hou, R. Jing, J. Pang, L. Zhang, X. Lu, X. Wei, G. Liu and Y. Yan, J. Alloy. Comp., 2019, 784, 931-938.

24 X. Lu, L. Hou, L. Jin, L. Wang, Y. Tian, K. Yu, Q. Hu, L. Zhang and X. Wei, Ceram. Int., 2018, 44, 5492-5499.

25 X. Lu, L. Wang, L. Jin, Q. Hu, Y. Tian, L. Hou, K. Yu, L. Zhang, X. Wei, Y. Yan and G. Liu, J. Alloy. Comp., 2018, 753, 558-565.

26 N. Liu, R. Liang, Z. Zhou and X. Dong, J. Mater. Chem. C, 2018, 6, 10211-10217.

27 N. Sun, Y. Li, Q. Zhang and X. Hao, J. Mater. Chem. C, 2018, 6, 10693-10703.

28 T. Li, X. Lou, X. Ke, S. Cheng, S. Mi, X. Wang, J. Shi, X. Liu, G. Dong, H. Fan, Y. Wang and X. Tan, Acta Mater., 2017, 128, 337-344.

29 F. Li, X. Hou, J. Wang, H. Zeng, B. Shen and J. Zhai, J. Eur. Ceram. Soc., 2019, 39, 2889-2898.

30 L. Wang, W. Bai, X. Zhao, F. Wen, L. Li, W. Wu, P. Zheng and J. Zhai, J. Mater. Sci.: Mater. Electron., 2019, 30, 9219-9230.

31 X. Lv, J. Wu, J. Zhu and D. Xiao, Phys. Chem. Chem. Phys., 2018, 20, 20149-20159.

32 R. A. Malik, A. Hussain, A. Maqbool, A. Zaman, T. K. Song, W.-J. Kim and M.-H. Kim, J. Alloy. Comp., 2016, 682, 302-310.

33 L. Chen, H. Wang, P. Zhao, C. Zhu, Z. Cai, Z. Cen, L. Li and X. Wang, J. Am. Ceram. Soc., 2019, 102, 4178-4187.

34 M. Xu, B. Peng, J. Zhu, L. Liu, W. Sun, G. J. T. Leighton, C. Shaw, N. Luo and Q. Zhang, J. Alloy. Comp., 2019, 789, 303-312.

35 M. Zhou, R. Liang, Z. Zhou and X. Dong, J. Mater. Chem. C, 2018, 6, 8528-8537. 